\title{
THE WHEEL OF FIRE AND THE MATING GAME: EXPLAINING THE ORIGINS OF TRAGEDY AND COMEDY
}

\author{
DANIEL NeTtLe \\ Division of Psychology, Brain and Behaviour \\ University of Newcastle
}

\begin{abstract}
Drama (on television, film or stage) is the most popular of all modes of fictional cognition. Drama consists of direct representation of a fictional social network in which characters have conflicting desires. It is dominated by two main genres: tragedy, which generally concerns status competition, and comedy, which generally concerns the process of mate selection. I argue that the evolved mind is intrinsically interested in information about the attempts to maximise fitness by individuals in the surrounding group. This is because such information is useful for optimising the individual's own behaviour. In particular, the strategies of others with regard to status attainment and mate selection impinge directly on our fitness and so have strong attention-grabbing power. I argue from analyses of Twelfth Night and Richard III that comedies and tragedies appear well designed to exploit these informational biases of the mind. This may explain the enduring appeal of the genres.
\end{abstract}

Keywords: evolutionary psychology, drama, tragedy, comedy, Shakespeare

\section{INTRODUCTION}

One of the most remarkable attributes of human beings is their propensity to engage with worlds that are imaginary. If other species attend to non-veridical narratives, and we have no evidence that they do, those narratives are private and internal to one individual. In the human case, by contrast, all cultures create stories that are shared, are attended to jointly by several people, and continue to hold attention despite being universally known to be false. These are not peripheral activities; the world of fiction and myth engages a great deal of time and energy in societies both affluent and under the most basic of conditions. There are two key questions concerning the origins of this attention to the imaginary. First, why should human beings be predisposed or vulnerable to attending to non-veridical events in the first place? Second, why do particular forms of shared representation persist and hold attention, rather than other logically possible ones?

The two questions may in fact be best tackled together, since it is not non-veridical representations in general that humans are predisposed to attend to, but rather, 
particular classes of representations, that vary from culture to culture but might turn out to have some universal similarities or tendencies. Thus the central question is simply: why do we engage in the fictional cognition that we do? By fictional cognition, I mean cognition about non-veridical scenarios, represented verbally, visually or kinetically, where knowledge of the non-veridical nature does not lead to a cessation of attention.

Most literary scholarship is generally, and for its own legitimate reasons, particularist and historicist. That is to say, the questions posed are most often at the level of why particular genres of representation might have evolved, or become prominent, or been interpreted in a certain way, at specific historical or cultural moments. The explanations are generally historicist in that they refer to earlier or later artistic forms, or wider socio-cultural forces, rather than to general properties of human beings. However, such work must in fact rely on a tacit universal psychology, even if this is never made explicit. This is because the maintenance, destruction and reinvention of artistic genres, and the reinterpreting of life in art, are all done by networks of minds. These minds cannot be conceived of as passive blank slates, since if they were there would be no reason at all for culture to evolve in one way rather than another. Minds must be active reshapers, reinterpreters and ignorers, or all cultural change is meaningless drift, and a dramatic form consisting of long strings of numbers read out by a single actor could become just as popular as a Christmas tearjerker. Thus, as Claude LEVI-STRAUSS once observed, when we talk about culture, the mind is there like an uninvited guest; not mentioned but necessarily present .

In recent years, a paradigm of Darwinian literary and artistic studies has begun to emerge (CARROLL 1995, 1999; GotTSCHALL and WiLSON 2004). Much of the work has dealt with specific genres and periods - romantic fiction (WHISSEL 1996) or Homeric epic (GoTTSCHALl 2001), for example. However, the common feature is a commitment to strengthening and making more explicit the universal principles based on the evolved mind that all human beings share, within which particularist and historical studies of the arts must be nested.

As regards the central question of why fictional cognition exists, a spectrum of different approaches has been taken. Broadly speaking, this spectrum is defined by the utility to the individual or group that imaginary representations are assumed to have. At one end of the spectrum is the idea that attending to fictional narratives directly enhances fitness is some way. The candidate benefits that have been proposed involve the generation of group solidarity (ROEDERER 1984), the opportunity to display and assess mate choice characteristics (MILLER 2000), and the transmission of social and behavioural norms (WILSON 2004). It is likely that art at various times fulfils all these functions, though whether art should be considered an adaptation for any of these, rather than a human propensity that can be exapted to all of them, remains an open question. 
At the other end of the spectrum are memetic approaches, in which the imaginary narratives are conceptualised as "memes" or replicators in their own right (AUNGER 2000). These "viruses of the mind" piggy-back on the fact that humans transmit information socially from one individual to another. The capacity to do this, it is argued, originally arose in order to transmit useful information, but non-veridical memes that were effective at getting transmitted crept in and proliferated, whilst those less effective gradually disappeared. It makes no sense under this conceptualisation to ask what the fitness benefits to humans are of entertaining fictional memes in their brains. Rather, their mental space is parasitised by non-veridical representations that are furthering their own reproduction, not that of their hosts.

All Darwinian approaches, however, predict that genres of fictional cognition will adapt themselves to the architecture of the minds through which they must be transmitted. If they are parasitic memes, those that endure will be those best able to compete for representational space in minds (DENNETT 1990). If they are mating displays or transmitters of social norms, then it is still the case that those which can best sequester attention and memory from human minds will be those which proliferate and endure. So all approaches predict an adaptation of artistic forms to the structure of the human mind. This means that the Darwinian programme in literary studies can proceed to some extent without a definitive resolution to the question of how the persistence of art itself is to be explained.

The aim of the Darwinian programme in may ways shares much with classical structuralism (GARDNER 1972; LEVI-STRAUSS 1967), which also aimed to explain patterns of myth and culture in terms of the mind. The difference is, however, that structuralism's model of the mind consisted only of formal operations (specifically, the mind was organised in terms of binary oppositions). This is a very under-specified mind that could generate pretty much any content, and yet at the same time is too rigid to generate the ambiguity and openness typical of human meaning (BARTHES 1974). The mind viewed from evolutionary psychology, by contrast, is endowed with innate domain-specific content, and a myriad of different reasoning modes (ТоOвY and Cosmides 1992), so it could in principle provide richer explanation of observed cross-cultural regularities in the content of the arts.

This paper concerns the evolution of the dramatic mode of fictional cognition, and in particular, the comic and tragic genres (section 3). However, I will begin by discussing what we know of the adaptive problems that human minds are designed to solve, which allows some predictions to be generated about the types of fictional representations which might be most effective at getting themselves noticed. As a result of this, I will argue that the deep appeal of the dramatic mode, and in particular comedy and tragedy, is easy to explain. Thus, once such a form had arisen, it is no surprise that it rose to cultural pre-eminence and endured for so long. Analyses of one comedy (section 4) and one tragedy (section 5) are given in support of these contentions. 


\section{PSYCHOLOGICAL FOUNDATIONS OF DRAMA}

He who understands baboon would do more toward metaphysics than Locke

- Charles Darwin

Human beings belong to the order of primates. They are often characterised as the exceptional primate, which obviously they are in terms of language, culture and so on. However, human beings are not aberrations; in many ways, they are merely the most clear or extreme example of tendencies that characterise the whole order, and especially the monkeys and apes. Primates, for example, have relatively large brains. This tendency is increasingly marked from prosimians up through New and Old World monkeys to apes. We stand not as an exception, but as the summit of a tree. Another essential characteristic of most primates is their sociality (DUNBAR 1988; SMUTs et al. 1987), with most species living almost all their lives in groups of a handful to a few dozen individuals. Again, the tendency becomes more marked up through the order and culminates in us.

Primate social groups have special characteristics that differ from, say, the social groups of bees and ants. Bees and ants are locked into hereditary castes dictated genetically and regulated physiologically. Primate groups, by contrast, are much more dynamic. Individual animals have places within a status hierarchy that determines mating and resource holding, but this hierarchy is constantly renegotiated through behaviour. Status may be achieved by direct physical dominance, through the formation of coalitions based on reciprocity, or through piggybacking on the dominance of kin. Status is desirable to achieve as it determines access to food and, most importantly, the likelihood of reproduction. Low ranking individuals can suffer considerable physiological stress (KEVERNE, MARTENSZ and TUITE 1989).

Within primate societies, "cliques" and "groups" can be distinguished (KUDO and DUNBAR 2001). The group is the total number of individuals that travel, feed or sleep together. Cliques are smaller sets of individuals within this who have stronger than average direct relationships with each other. The total group is tight; any two individuals in a group can usually be linked either directly or by one remove; either they are in a clique with each other, or they are in a clique with someone who is in a clique with the other. The "social glue" that holds this intricate arrangement together is grooming. Wild primates spend up to $20 \%$ of their time going through each other's fur, removing parasites (DUNBAR 1993). Subordinates groom superiors, alliance partners groom each other, kin are tended, potential mates flirt, outcasts go ungroomed.

One consequence of the flexibility of primate social systems is that you need to keep track of a lot of social knowledge. A bee can smell who is a worker and who a drone; a monkey has to remember who is dominant and who subordinate by close observation of who has been grooming who. A bee knows who has the right to reproduce and who not, because only the queen has, and her physiology is an indelible 
mark; a monkey has to work out, negotiate, remember. Since primate rank is not entirely hereditary, life contains vicissitudes, including the possibility of rising to dominance, and the risk of falling from it, all contingent, all dependent on one's own behavioural decisions and the reading and remembering of the behaviour of others. It follows from this that the larger the social group a primate lives in, the more complex the psychological task it needs to perform to behave in an adaptive way. This is because as the group size increases, the number of relationships one needs to observe and keep track of rises exponentially.

Robin DUNBAR has shown that, across primate species, the larger the social group, the larger the relative size of the neocortex, the "higher cognitive" part of the brain (DunBar 1993; KUdO and Dunbar 2001). More social information to track demands more computing power to do it, even at the evolutionary cost of laying down more cerebral tissue, one of the most metabolically expensive tissue types we have in our bodies (AIELLO and WHEELER 1995). And humans have the largest neocortices of all, suggesting what common observation shows to be true, that our nature is to live in large and complex social formations. One consequence of this fact is that observing social interaction within a group (seeing who is with whom and what they are doing together) is inherently attention-grabbing, well-remembered and salient.

As Dunbar has cogently argued, social groups as large and complex as ours would be very difficult to keep track of by grooming relationships alone. To directly observe all the pairwise grooming relationships amongst even a modest hunter-gatherer band would take a lot of time, and to groom or be groomed by every other individual even more so. But human beings have language. We can share social information. " $\mathrm{X}$ is trying to curry favour with $\mathrm{Y}$, so $\mathrm{Y}$ will cooperate in supplanting your father Z", we can say. This has the double advantage of quickly disseminating useful information, and of creating a reciprocal bond between speaker and hearer, which is itself a kind of coalition that may come in handy later. Language binds us together as grooming binds monkeys and apes (DUNBAR 1993).

Place a group of monkeys or apes in a room together, and if they do not fight or mate they will groom each other. Repeat the same experiment with a group of people, and if they do not fight or mate, they will talk. And DunBAR's observational studies suggest that they will talk overwhelmingly about the social worlds they inhabit (DUNBAR, MARRIOTT and DUNCAN 1997): people they know in common, the behaviour of other individuals, their own relationships. Technological, institutional, philosophical or aesthetic matters may intrude, but most natural conversations will soon return to the social network within which all of these other activities are embedded. For monkeys and apes, grooming releases the body's endogenous opiates, which is why they find it so rewarding (Keverne, Martensz and Tuite). In humans, it seems that language may have sequestered this mechanism; we like nothing better than a good conversation. 
Conversations, then, are activities we are inherently motivated to seek, for good reason to do with our evolutionary past. Any activity which could mimic the relevant features of a really good conversation would be extremely potent at capturing our attention. Good conversations are proto-typically concerned with exchanging information about the vicissitudes of relationships within a small social group.

The foregoing paragraphs lead to very simple predictions. Evolution will have provided us with cognitive mechanisms or biases towards observing and tracking the behaviour of others within a social context, and attending strongly to information about such behaviour that might be given to us by third parties. We should find people-watching and gossip intrinsically rewarding Thus any fictional cognitive activity which involved (a) direct observation of key interpersonal behaviours (for what "key" might mean, see below), and/or (b) shared information about social group motivations, deceptions and coalitions should strongly and persistently engage attentional mechanisms.

Conversations are only interesting to the extent that you know about the individuals involved, and your social world is bound into theirs; as their distance from you increases, the interest level declines away. Fictional social cognition, which is based on invented individuals, has to compensate for this effect somehow. One way is for it to be not just a simulacrum of ordinary social cognition, but an intensified simulacrum. That is, the content of the cognition has to be at the maximum interest level possible in order to hold onto receiver attention, equalling or even exceeding the most attention-worthy aspects of real life. This is like the "supernormal" stimulus effect in animal behaviour. An egg elicits nesting behaviour from a female gull; a football elicits an abnormally strong nesting reaction (TINBERGEN 1951), even though eggs as big as footballs do not actually exist.

What does this "supernormal conversation" hypothesis predict more particularly? We have stated that human beings evolved in small, tight knit social groups in which one person's opportunity to maximise fitness was closely bound up with the attempts to do so by all the others. Much conversation thus typically concerns behaviour by other people in our circle in relation to their attempted maximisation of their biological fitness; their illness, health, mating, rises and falls in status and coalitions and so on. The more extreme the fitness stakes, the greater the interest level. Betty going shopping is a lot less interesting than Betty leaving her husband for another man, because its effect on her fitness is much more significant, and, in a small-scale society, it would have a likely effect on our fitness, because there weren't many other mates to choose from, and the individuals involved were likely to be our allies or kin.

We would thus predict that as the fitness-change stakes go up, the attentiongrabbing power of a story would increase. In particular, we should be especially interested in attempts by others to sequester scarce social resources. The key social resources in any primate society are status and mates. Members of both sexes, but 
males in particular, seek to maximise status with a combination of coalitional behaviour, deception, and direct physical confrontation. The way others around us are doing this is so important to us because status is inherently non-zero sum, and thus someone else's rise may be our fall. Potential mates are also limited in number, and so we should attend to who is looking like pairing off with whom. Thus, a supernormally interesting conversation would be one about status competition so severe it led to the death of one or more of the parties, and/or the process of pairing mates together in our immediate social group.

In a small-scale society, the attempts at fitness maximisation by one individual would be bound to impinge heavily on others, and this will bring about conflict. What is more, there can be conflict within one individual between the possible pathways for fitness maximisation. In primate societies, the ultimate goal of fitness maximisation decomposes into several distinct more proximate goals. At the most basic level, we can identify the following fundamental sub-goals:

1. Self-preservation. An animal should stay healthy, which means being well fed and keeping away from fights and predators.

2. Mating. An animal should seek to mate when opportune. Males need to ensure the fidelity from their females, in order to be sure of paternity, whereas in altricial species females need to secure post-reproductive investment from their males.

3. Status. An animal should maximise its position on the status hierarchy, as this dictates access to mates, and resources in times of scarcity.

4. Coalition formation. An animal should maintain its coalitions.

5. Kin. An animal should protect the interests of its kin.

(For a very similar list, see CARROLL 1999.)

All organic life involves trade-offs, and in primates these 5 goals are often in conflict, suggesting different strategies in the game of life. Should I seek the mate I want (2) even at the risk of physical danger (1) or the wrath of my friends (4)? Should I seek the alpha status position (3), even at the expense of my kin (5)? There is no definitive answer to these questions. The future can only be guessed at, and besides, the outcome of me choosing one course will depend on what everyone else decides to do. Thus the dilemma resonates ceaselessly; solutions can be guessed at but never known. These are the universal problematics of our order. Any primate should be interested in how other individuals solve them, for two reasons. First, it will have to solve them too, and seeing the result of someone else's negotiation of them might provide a partial model. Second, in the tight groups, the way one individual solves them will have direct effects on the fitness prospects of all the others too.

Given all these considerations, we can derive a design specification for a fictional form that would have an extremely strong intrinsic capture potential for human minds. 
(i) It should essentially involve the observation and conveyal of social information about relationships within small tight groups similar to those typical of our species' natural behaviour.

(ii) These groups should interact in smaller units with especially strong relationships (cliques).

(iii) The individuals involved should make attempts to maximise their biological fitness, with reference to goals $1-5$ above.

(iv) The more extreme the fitness stakes, the greater the intrinsic interest. The most significant domains are mate choice and status competition, and the extreme outcomes in these domains are mating and death.

(v) The attempts by the protagonists to maximise their fitness will bring about conflict, either between different individuals, or between different sub-goals for one individual. The richer and more complex these conflicts, the more captivating the product will be.

In the next section, we search for a fictional form in Western culture that fulfils these criteria.

\section{THE DRAMATIC MODE}

$$
\begin{aligned}
& \text { All tragedies are finished with a death } \\
& \text { All comedies are ended with a marriage } \\
& \text { - Byron, Don Juan }
\end{aligned}
$$

The dramatic mode is perhaps the dominant mode of fictional representation in Western culture. This was not always the case. As Aristotle argues in chapter 4 of the Poetics, the dramatic mode was developed in the 5th and 4th centuries BC in Greece, when the epic (story-telling) mode of performance was expanded to include more actors, who directly represented interactions in dialogue, rather than describing them. Once established, however, the mode has dominated the whole history of Western theatre, and subsequently film, television, and now interactive video gaming and other new media experiences. The essence of the dramatic mode is that characters in a story are directly impersonated (by actors), rather than being talked about by a narrator. Thus, drama is a mimetic art.

Dramatic modes have developed apparently independently in diverse cultures at diverse times. I make no argument that the dramatic mode is cross-culturally universal, or historically inevitable, or the only effective way of telling a story. Rather, I wish to argue that drama, as it has evolved in the West, has developed a set of structural features that make it enduringly powerful, and these features can be understood in terms of the adaptation of the genre to the evolved minds of the audience. Overlaid over these general tendencies, of course, there will be specific historical 
factors that may explain the development of particular types or interpretations of dramas at particular times. But underlying these is a general attention-grabbing power of the dramatic mode that is probably universal.

Drama consists of the creation of a (fictional) tight-knit social group. The audience has the chance to directly observe social interaction, but also - usually - to be part of a conversation between the characters about what is going on within the group. The groups depicted, like real human social networks, typically consist of blood relatives, and coalitional cliques, and sometimes a few strangers. Characters have wants or objectives, and these belong ultimately to the set of basic motivations (1) to (5) (above). Often those wants conflict with those of the other characters (and other wants of the same characters), and the work of the play is to resolve those conflicts.

These characteristics already mean that dramatic presentations should have high attention-grabbing power for our evolved social cognitive mechanisms. Other features make this even more strongly the case. First there is the size and structure of the group. The number of characters in a drama rarely exceeds two or three dozen (see Stiller, NetTle and Dunbar [2003] for Shakespeare, for example). This is a number of the same order as an average person's close social network (HILL and DUNBAR 2003), so well within the number of relationships we are attuned to keeping close active track on. Within the group portrayed, characters either interact directly or are separated by at most one intermediate link in a chain of interaction. Thus, everyone is closely enough connected for their behaviour to influence everyone else's, and in particular for their fitness striving wants to cause non-zero sum conflict with those of others. This re-creates what surely must have been the situation of ancestral human societies. Most interestingly, the audience, necessarily, is directly connected to every character that appears on the stage. The audience often knows more about what is going to happen than any particular character, and, through devices such as asides and soliloquies, is the most informationally privileged member of the social group.

Second, the content of the conflicts depicted is such as to make them especially attention grabbing. Right from classical times, dramas have mainly been discussed in terms of two categories: comedies and tragedies. These categories apply fairly accurately for most dramas for the entire intervening 2500 years. Tragedies involve serious, often political, conflicts, usually leading to a negative outcome for the protagonist. Comedies typically involve conflicts that tend to the ridiculous and which are positively resolved. Thus, Byron's heuristic (quoted above) separates the two classes reasonably well. If there is marriage after the final death, it is usually a comedy, and if a death after the final marriage, usually a tragedy.

I will argue that tragedy and comedy quintessentially represent explorations of the domains of status competition (tragedy), and mate choice (comedy). Thus, they are 
the dramatic forms that fulfil feature (iv), above. Tragedies generally end with a death because that is the logical extreme fitness change that can arise from status competition. Comedies generally end with a marriage, because that is the key fitness-change event that can arise from mate choice procedures. These generalisations hold quite widely. However, the best way to demonstrate them is to take a concrete analysis of some representative plays. In the next two sections, I present such an analysis, taking two Shakespearean dramas, Twelfth Night (a comedy), and Richard III (a tragedy, for present purposes). Shakespeare has been chosen for several reasons. I will argue that the main lines of tragedy and comedy run all the way from classical theatre to contemporary cinema, and Shakespeare stands chronologically at the centre of this cultural history. He is also culturally at its centre too, as the dramatist whose works have been most performed and reinterpreted, not just in the land of his origin, but all over the world (BATE 1997). Almost any Shakespearean (or other) play could be analysed in the manner presented here, but these are two particularly interesting examples.

The technique of analysis is to show how the play can be understood in terms of (a) desires by different characters to maximise their biological fitness by either mating, status enhancement, coalition building, or kin nepotism; (b) the conflict engendered by different characters' conflicting fitness desires; (c) some kind of structural perturbation of the matrix of fitness desires that allows the conflict to be overcome; and (d) extreme changes in biological fitness as the outcome of the action.

\section{TWELFTH NIGHT}

Twelfth Night (1600-1602) is the story of two twins, Sebastian and Viola, who are washed up in a strange country by a shipwreck. In that country is a noble lady, Olivia, who is wooed by the local Duke Orsino, and also by a clownish knight Sir Andrew Aguecheek. Aguecheek is a close friend of Olivia's cousin Sir Toby Belch. One of Olivia's servants, Malvolio, is also in love with her.

Viola, alone in a strange country, adopts male disguise, and passing herself off as a boy called Cesario, is employed by Orsino as a servant. In the course of her duties carrying messages between Orsino and Viola, both Viola (thinking she is a young man), and Orsino (detecting her feminine qualities) are smitten with her. The love knot is untied when Sebastian, her male twin, turns up, since she can now reveal her true sex and marry Orsino, whilst Sebastian is only too happy to marry Olivia. In a sub-plot, Belch and Malvolio vie for status within the household and Malvolio goes away, having been shamed in a plot devised by Sir Toby Belch and the servant girl Maria. Maria impersonates Olivia's hand-writing to trick Malvolio, and Belch is so impressed that he marries her. 
We can express the structure of Twelfth Night in terms of a number of heavily interlocked fitness volitions. Orsino wants to marry Olivia. Olivia wants to marry Viola (as Cesario), and Viola wants to marry Orsino. This is the interlocked fitness dilemma at the heart of the main plot. The characters in a small group have nonsymmetrical mate choice preferences, as a result of which nobody can mate despite the availability of potential mates of both sexes. Meanwhile, in the sub-plot of lower ranking individuals, both Sir Andrew Aguecheek and Malvolio also want to marry Olivia. In Malvolio's case it is one strand is his attempt to rise in status, vis-à-vis Sir Toby Belch. Sir Andrew Aguecheek is a natural coalitionary partner for Belch in his battle against Malvolio, for he is spurred on by the thought of access to Olivia, and the Belch-Aguecheek coalition is naturally inimical to Malvolio's status and mating interests. Maria for her part wants to marry Belch, but is of lower status than him and thus needs to prove herself to do so.

This interlocked structure is completely irresolvable without some perturbation or transformation of the matrix. A list of the main fitness volitions is shown in Table 1. For each, I have specified the agent, the action (in terms of the fundamental motivations, $1-5$, above), and the other individuals implicated. I have also specified which of the other actions provide an obstacle to each other. The ten listed would seem to be the primary ones; secondary issues follow, such as Olivia's conflict over whether to throw Belch out; on the one hand he is an obstacle to her match with Viola as Cesario, on the other he is kin.

Table 1. Structure of interlocking fitness volitions in Twelfth Night

\begin{tabular}{rlllc}
\hline & Agent & Action & Target & Obstacle or counterpoint \\
\hline 1 & Orsino & Mating & Olivia & 2 \\
2 & Olivia & Mating & Viola as Cesario & 3 \\
3 & Viola & Mating & Orsino & 1 \\
4 & Aguecheek & Mating & Olivia & 2 \\
5 & Malvolio & Mating & Olivia & 2 \\
6 & Malvolio & Status & Belch et al. & 7 \\
7 & Belch & Status & Malvolio & 6 \\
8 & Belch & Coalition & Aguecheek & 4,6 \\
9 & Maria & Mating & Belch & Low status \\
10 & Sebastian & Mating & Olivia & 2 \\
\hline
\end{tabular}

The work of the plot is to transform the matrix structurally, so that each of the ten actions is either achieved or becomes definitively impossible, resulting in change in status and fitness for the relevant characters. In fact, with remarkable economy, only two transformations are needed to do this. The first is the substitution of Sebastian for Cesario. The offstage narrative of the twins and the shipwreck allows this exchange of targets at the heart of the resolution: one person (Viola) who can logically 
only be of one sex and marry one spouse, is replaced by a pair of twins, one of each sex, who can take two spouses. Olivia's marriage to Cesario/Sebastian is now unblocked, and Aguecheek's, Malviolo's and Orsino's suits made impossible (Belch's coalition with Aguecheek is now destroyed too). Once Sebastian replaces Cesario, Viola can reveal her true identity and actions 1 and 3 can be fulfilled. The third transformation is the successful impersonation of Olivia's handwriting by Maria. This allows Belch to triumph over Malvolio; Maria thus rises in Belch's esteem to the point where he marries her.

Thus, in a very simple way, all ten volitions are resolved. The play ends with three weddings as the characters whose fitness has increased cement the bond, and the characters whose fitness has fallen disperse (Malvolio, Aguecheek). The play's particular strength is cramming a maximal richness of conflicting actions into a small group, and resolving them by a remarkably simple set of contrivances.

Shakespeare's comedies all have essentially similar structures; a central set of potential couples ( 2 in A Midsummer Night's Dream and Much Ado about Nothing, 4 in Love's Labour's Lost, and so on) and related mating motivations, obstacles or confusions in the path of these, and structural transformations of the network which unblock the matrix of desire. The result is always a marriage, be it double, triple or quadruple. And this pattern continues into contemporary culture, with romantic movies such as When Harry Met Sally and Four Weddings and a Funeral concerning the playing out of the dynamic of mate choice, finally resolving in a wedding or mating.

\section{RICHARD III}

Richard III (1592) is the story of the rise and fall of Richard, Duke of Gloucester, who was King Richard III of England from 1483 until his death in 1485. It is the fourth and final part of a series of plays that tells the story of the Wars of the Roses and civil strife of England beginning in 1485. Since the play is based on historical events and non-fictional sources, it is usually classified as a history, distinct from the tragedies such as Othello and Hamlet. However, Richard III and several other of the history plays exemplify well the main features of tragedies, and so we will consider it as such for present purposes.

The play is dominated by one of Shakespeare's most memorable central characters, and equally dominated at a structural level by a single fitness volition: Richard, Duke of Gloucester's desire for status (exemplified, as so often in Elizabethan drama, by the crown of the kingdom). The play can be seen as the tale of four high status men. Henry VI, the former king whose clan was deposed by Richard's, is already dead by the time the action of the play begins, but his presence lives on, as we shall see. Edward IV, Richard's older brother, is on the throne at the beginning of the play. 
Richard becomes king by the middle of the play, and Henry of Richmond becomes King Henry VII in the denouement.

Richard faces a trade off amongst competing motivations. His fitness could be enhanced by becoming king. He has already played a key role in the destruction of the Lancastrian clan, and the placing of a Yorkist (his own brother) onto the throne. Now there are few individuals ahead of him in succession. The problem is that they are his own older brothers, Edward IV and the Duke of Clarence, and their children. Thus, a kin protection motivation is finely balanced by status enhancement one.

There is no universal solution to such dilemmas, and drama represents to some extent the playing out of different possible strategies. The theory of kin selection does not predict that individuals will never harm kin; only that they will only do so if the benefit is very great, which in the case of the crown, it is. One could envisage a continuum of responses from giving the kinship motivation greatest weight, to giving it least. Richard's strategy represents the latter extreme, perhaps, as often suggested by characters' own understandings, pathologically so. Richard's strength of will is the central motor of what happens.

Richard's rise and fall can be plotted in terms of support networks. Across the primate world, a subordinate will usually require coalition partners to displace a dominant male. The extent to which others can be recruited to such a coalition depends on what is on offer; if they can be made to believe their fitness will be enhanced in the process, they will join. At the beginning of the play, Edward IV has an impressive support network in his new role of king; not only his own brothers, Clarence and (as he thinks) Richard, but his wife Elizabeth and her extensive kin (Rivers, Vaughan, Grey, Dorset), as well as the high-ranking professional politicians (Buckingham, Stanley, Hastings). The only dissenters are represented by the young widow Anne and the former Lancastrian queen Margaret. They are the members of the former king Henry VI's support coalition who have not been successfully drawn on board by Edward.

Richard's action is twofold; he mops up Henry VI's residual coalition by marrying the deceased king's widowed daughter-in-law Ann. Ann can be little enthused by the prospect, but since the fall of the Lancastrians she is left utterly without a support network. Richard's offer may be her least bad option. Richard also sets out to destroy Edward's coalition by building up his own. He first uses machinations to engineer between Edward and Clarence a mistrust that leads to Clarence's execution without Richard seeming to be implicated. Edward's subsequent shock at having so violated his kin-protection drives without fully meaning to leads to his death. The natural succession would pass to Edward's children, but they are still too young to maintain dominance. In the vacuum, Richard picks apart their father's coalition. Buckingham is lured by promise of an estate under the new order. Hastings is sounded out for a similar defection, but, seeming unwilling, is hastily executed. Rivers, 
Vaughan and Grey (but fatefully for Richard not Dorset) are executed on trumped up charges.

Thus by the middle of the play, the young sons of Edward IV, too insubstantial to maintain dominance without a support network, are completely lacking a coalition, and are marginalised and eventually killed. Richard has assembled Ann and Buckingham and a host of lower ranking nobles and political groups, and has removed opponents like Hastings from the picture. However, Richard's one-sidedness in pursuit of his status enhancement, which has been his strength in ascent, becomes his flaw. Coalitions can only be maintained by reciprocity. Despite becoming king, Richard fails to deliver Buckingham's bait of material enhancement. Buckingham flies to the young duke of Richmond, as does Dorset, whose own social network has been massacred by Richard. Richmond's support network grows. Stanley would defect, but Richard holds his son hostage, thus binding Stanley unwillingly into the coalition by his own kin-protection motivation. Richard relies on lower and lower ranking allies to do his purposes, and in desperation now tries to recruit Elizabeth, who holds him off whilst actually supporting Richmond.

The final battle at Bosworth field is essentially a formality; the structural work of the drama has been done by the changing composition of the different support networks through time (Table 2). Richard III has often been seen as a study of the tyrannical individual, informing, for example, Brecht's study of Hitler in The Resistible Rise of Arturo Ui, but it can equally be seen as an exploration of the dynamics of social coalitions. An individual can rise in status to the extent he is adept at creating a coalition, by playing on the fitness, kinship and self-protection motivations of others; but his status cannot be maintained unless he is also adept at keeping the coalition going, through reciprocal reward of his partners. Betrayals and failed promises come, quite literally, back to haunt Richard, and in end, the quality and weight of the social coalition is always the determinant of the outcome. As before, the changes of state explored in the play are the logical maxima on the dimension of the action; kingship, which is maximal conceivable status, or death.

The path of Richard III up, and then down, the status-fitness hierarchy is an exemplar of a clear model that runs through all of Shakespeare's history plays, and many of the tragedies (indeed some of the comedies too, such as As You Like It and The Tempest). It is what Jan KотT calls the 'grand mechanism' of history (КотT 1974). One man struggles to reach the top; he does so by a combination of direct power and coalition; in turn he is displaced by the next generation coming up behind. We hope that a more peacable social order will descend on us; that coalitions and consensus will hold ambition at bay, but there is a gap between what we might hope for, the fragile and cherished good of cooperation, and what happens. It is never long before the next challenge, be it battle or murder or rebellion, comes along. 
Table 2. Support coalitions in Richard III

\begin{tabular}{|c|c|c|c|}
\hline \multicolumn{4}{|l|}{ Act one } \\
\hline Henry VIt & Edward IV§ & $\underline{\text { Richard }}$ & Richmond \\
\hline Margaret & Clarence & Hired thugs & Margaret \\
\hline \multirow{10}{*}{ Ann } & Buckingham & & \\
\hline & Hastings & & \\
\hline & Stanley & & \\
\hline & Queen Elizabeth & & \\
\hline & Rivers & & \\
\hline & Vaughan & & \\
\hline & Dorset & & \\
\hline & Grey & & \\
\hline & Young princes & & \\
\hline & Minor nobles & & \\
\hline \multicolumn{4}{|c|}{ Acts two-four } \\
\hline \multirow[t]{6}{*}{ Henry VI† } & Edward IVt & $\underline{\text { Richard } \S}$ & $\underline{\text { Richmond }}$ \\
\hline & & Ann & Margaret \\
\hline & & Buckingham & \\
\hline & & Stanley & \\
\hline & & Mayor and citizens & \\
\hline & & Minor nobles and hired thugs & \\
\hline \multicolumn{4}{|l|}{ Act five } \\
\hline \multirow[t]{6}{*}{$\underline{\text { Henry VIt}}$} & $\underline{\text { Edward IVt }}$ & $\underline{\text { Richard } t}$ & Richmond $\S$ \\
\hline & & Minor nobles and hired thugs & \\
\hline & & & Buckingham \\
\hline & & & Elizabeth \\
\hline & & & Stanley \\
\hline & & & Margaret \\
\hline \multicolumn{4}{|l|}{$\dagger$ Dead§ } \\
\hline King & & & \\
\hline
\end{tabular}

\section{FROM DIONYSUS TO DIE HARD: UNDERNEATH NEW CULTURE LIES OLD PSYCHOLOGY}

Lechery... still wars and lechery. Nothing else holds fashion. - Shakespeare, Troilus and Cressida

We have seen how the evolutionary principles expounded in section 2 compellingly apply to a representative comedy (section 4) and a tragedy (section 5). Comedy centrally concerns the procedure of pairing up sexually eligible individuals within a small group to everyone's satisfaction. Its denouement is therefore marriage. Tragedy essentially involves competition for status within a social group; it may 
involve the attainment of dominance, perhaps temporarily, but its logical outcome is death. Both forms have high intrinsic attention-grabbing power because they are intensified conversations in the social domains that, because they affect our fitness most, we are most interested in. Independent evidence for this cognitive bias comes from the newspapers, which are full of stories of bitter rivalry, and the mating game.

It is beyond the scope of this paper to show that similar analyses can be applied to tragedy and comedy of different historical periods, or different cultures, though these are important researches to begin. Suffice it to say that the modern romantic comedy and action film are astonishingly directly related to Twelfth Night and Richard III. The classification should perhaps be a little more complex than I have presented here (NETTLE 2004). In fact, there would seem to be four key types of dramatic plot (Table 3). As well as the question of whether the central fitness action is the mating game or status competition, there is the question of whether the ultimate change in fitness for the characters with whom the audience is most allied is positive or negative. Thus, a mating game with positive fitness outcomes is a comedy, like Twelfth Night or Four Weddings and a Funeral, whereas a mating game with negative fitness outcome is a love tragedy, like Romeo and Juliet, or Hedda Gabbler. A status game with positive fitness outcome for the central character is a heroic, like Die Hard or Henry V. A status game with negative fitness outcome is a tragedy, like Othello or Taxi Driver.

Table 3. The four-fold classification of dramas (NETTLE 2004)

\begin{tabular}{|c|c|c|}
\hline \multicolumn{3}{|c|}{ Resolution } \\
\hline & Negative & Positive \\
\hline \multicolumn{3}{|c|}{$\underline{\text { Central Conflict }}$} \\
\hline$\underline{\text { Status }}$ & $\begin{array}{l}\text { Tragedy } \\
\text { e.g., Richard III } \\
\text { Taxi Driver }\end{array}$ & $\begin{array}{l}\text { Heroic } \\
\text { e.g., Henry V } \\
\text { Die Hard }\end{array}$ \\
\hline Mating & $\begin{array}{l}\text { Love tragedy } \\
\text { e.g., Romeo and Juliet } \\
\text { Hedda Gabbler }\end{array}$ & $\begin{array}{l}\text { Comedy } \\
\text { e.g., Twelfth Night } \\
\text { When Harry Met Sally }\end{array}$ \\
\hline
\end{tabular}

It is remarkable how many dramas, from any historical era, can be fitted easily into one of the four cells in this matrix. Of course, some have elements of several cells, and great art often exhibits a constantly shifting perspective (for example, back and forth between positive or negative as the audience's allegiances change). Nonetheless, the typology appears compelling.

The purpose of this paper has not been to argue that the dramatic mode, or comedy and tragedy, are in any way innate or direct products of our evolved psychology. 
They are social constructions with a particular historical origin and cultural history. Instead, the argument has been that that fictional representations must compete to garner human attention, and this influences the way that cultural traditions, drama in this case, evolve. It follows from what we know about the human mind that social information will have high attention-grabbing potential, and in particular information about how others in the social group around us are trying to maximise their fitness. Dramas appear well designed by cultural evolution to exploit this underlying psychology. Love and status in those around us are two enduringly interesting features of human interaction, and, because of this, millennial persistence of the comic and tragic forms is no surprise.

\section{REFERENCES}

Aiello, L. C. and WheElER, P. (1995): The expensive tissue hypothesis. Current Anthropology, 36, 199-211.

Aunger, R. (ed.) (2000): Darwinizing Culture: The Status of Memetics as a Science. Oxford: Oxford University Press.

BARTHES, R. (1974): S/Z. New York: Hill and Wang.

BATE, J. (1997): The Genius of Shakespeare. London: Macmillan.

CARRoll, J. (1995): Evolution and Literary Theory. Columbia: University of Missouri Press.

CARroll, J. (1999): The deep structure of literary representations. Evolution and Human Behavior, 20, 159-173.

DenNetr, D. (1990): Memes and the exploitation of the imagination. Journal of Aesthetics and Art Criticism, 48, 127-135.

Dunbar, R. I. M. (1988): Primate Social Systems. London: Chapman and Hall.

DunBAR, R. I. M. (1993): Coevolution of neocortical size, group size and language in humans. Behavioural and Brain Sciences, 16, 681-735.

Dunbar, R. I. M., MARRIOTT, A. and Duncan, N. D. C. (1997): Human conversational behavior. Human Nature - an Interdisciplinary Biosocial Perspective, 8, 231-246.

GARDNER, H. (1972): The Quest for Mind: Piaget, Levi-Strauss, and the Structuralist Movement. New York: Random House.

GotTsChall, J. (2001): Homer's human animal: Ritual combat in The Iliad. Philosophy and Literature, 26, 278-294.

GotTSChall, J. and Wilson, D. S. (eds) (2005): Literature and the Human Animal. Evanston, IL: Northwestern University Press.

Hill, R. A. and Dunbar, R. I. M. (2003): Social network size in humans. Human Nature, 14, 53-72.

Keverne, E. B., Martensz, N. and Tuite, B. (1989): Beta-endorphin concentrations in cerebrospinal fluid in monkeys are influenced by grooming relationships. Psychoneuroendocrinology, 14, 155-161.

Kотт, J. (1974): Shakespeare our Contemporary. New York: W. W. Norton.

Kudo, H. and Dunbar, R. I. M. (2001): Neocortex size and social network size in primates. Animal Behaviour, 62, 711-722.

LeVI-STRAuss, C. (1967): Structural Anthropology. New York: Anchor Books. 
Miller, G. F. (2000): The Mating Mind: How Sexual Choice Shaped Human Nature. New York: Doubleday.

NetTLE, D. (2005): What happens in Hamlet? Exploring the psychological foundations of drama. In J. Gottschall and D. S. Wilson (eds): Literature and the Human Animal. Evanston, IL: Northwestern University Press.

Roederer, J. (1984): The search for a survival value of music. Music Perception, 1, 350-356.

Smuts, B. B., Cheney, D. L., Seyfarth, R. M., Wrangham, R. W. and Struhsaker, T. T. (1987): Primate Societies. Chicago: Chicago University Press.

Stiller, J., Nettle, D. and Dunbar, R. I. M. (2003): The small world of Shakespeare's plays. Human Nature, 14, 397-408.

Storey, R. (1996): Mimesis and the Human Animal. Evanston, IL: Northwestern University Press. Tinbergen, N. (1951): The Study of Instinct. Oxford: Clarendon Press.

Tooby, J. and Cosmides, L. (1992): The psychological foundations of culture. In J. H. Barkow, L. Cosmides and J. Tooby (eds): The Adapted Mind: Evolutionary Psychology and the Generation of Culture. New York: Oxford University Press, 19-136.

WHISSEL, C. (1996): Mate selection in popular women's fiction. Human Nature, 7, 427-448.

WILSON, D. S. (2005). Evolutionary social constructionism. In J. Gottschall and D. S. Wilson (eds): Literature and the Human Animal. Evanston: Northwestern University Press. 